\title{
Understanding decision making in teachers' curriculum design approaches
}

Citation for published version (APA):

Boschman, F., McKenney, S., \& Voogt, J. (2014). Understanding decision making in teachers' curriculum design approaches. Educational Technology Research and Development, 62(4), 393-416.

https://doi.org/10.1007/s11423-014-9341-x

\section{DOI:}

10.1007/s11423-014-9341-x

Document status and date:

Published: 01/08/2014

Document Version:

Early version, also known as pre-print

\section{Document license:}

CC BY-SA

Please check the document version of this publication:

- A submitted manuscript is the version of the article upon submission and before peer-review. There can be important differences between the submitted version and the official published version of record. People interested in the research are advised to contact the author for the final version of the publication, or visit the DOI to the publisher's website.

- The final author version and the galley proof are versions of the publication after peer review.

- The final published version features the final layout of the paper including the volume, issue and page numbers.

Link to publication

\section{General rights}

Copyright and moral rights for the publications made accessible in the public portal are retained by the authors and/or other copyright owners and it is a condition of accessing publications that users recognise and abide by the legal requirements associated with these rights.

- Users may download and print one copy of any publication from the public portal for the purpose of private study or research.

- You may not further distribute the material or use it for any profit-making activity or commercial gain

- You may freely distribute the URL identifying the publication in the public portal.

If the publication is distributed under the terms of Article 25fa of the Dutch Copyright Act, indicated by the "Taverne" license above, please follow below link for the End User Agreement:

https://www.ou.nl/taverne-agreement

Take down policy

If you believe that this document breaches copyright please contact us at:

pure-support@ou.nl

providing details and we will investigate your claim.

Downloaded from https://research.ou.nl/ on date: 26 Apr. 2023 
PrePrint of: Boschman, F., McKenney, S. \& Voogt, J. (2014). Understanding decision making in teachers'

curriculum design approaches. Educational Technology Research and Development, 62, 393-416.

\begin{abstract}
The goal of this study was to reach a better understanding of the intuitive decisions teachers make when designing a technology-rich learning environment. A multiple case-study design was employed to examine what kinds of factors (external priorities, existing orientations or practical concerns) influence design interactions of teams of kindergarten teachers. This study combines semi-structured interview data on teachers' existing orientations with analysis of teachers' design discussions during the design of learning material for a technology-rich learning environment. Three teams of teachers voluntarily participated. Findings on the existing orientations suggest that knowledge and beliefs about teaching and learning related to knowledge and beliefs on technology and early literacy. The analysis of teachers' discussions revealed that the process could be characterized to a large extent as brainstorms; and that problems are not addressed in depth. Rather they are resolved through brainstorming, and most argumentation falls in the realm of practical concerns: how to organize learning activities and how to respond to contingencies. The findings of this study suggest that teachers' explicated design reasoning is mostly influenced by practical concerns, yet their own knowledge and beliefs play an important role at the start of the design process. However, these existing orientations as well as the practical concerns that emerge during the conversation tend to be narrow in scope. Theoretical and practical implications are discussed in light of how this study provides understanding of how to support these teachers.
\end{abstract}




\section{Introduction}

Contemporary research on technology integration in classrooms has pointed to the importance of teachers' involvement as designers. This approach to innovation has been advocated for several years (Clandinin, 1992) as a feasible and desirable way of reaching sustained innovation in practice. Active engagement may increase ownership, offer opportunity for professional development, and produce material that is more in line with classroom practice (Ben-Peretz, 1990; Borko, 2004). A growing number of studies in which teams of teachers acts as designers shows that those teachers actually yield progression in technology integration in their classroom (e.g. Koehler, Mishra, \& Yahya, 2007). In such design teams, teachers create learning material, collaboratively solve problems and reason toward solutions. However, little is known about the conversations in the teams. Teachers' own approaches to problem solving have been criticized as being inappropriate for complex design problems (Hoogveld, Paas, Jochems, \& van Merriënboer, 2001). Teachers often deliberate in terms of concrete classroom activity, attempt to adapt existing material, need support from an external facilitators to think about abstract issues such as subject-matter or a curriculum framework, and focus their attention on their students throughout the design process (Deketelaere, 1996; George \& Lubben, 2002; Handelzalts, 2009). This study takes the stance that a productive approach entails seeking understanding of what teachers naturally do and why. This approach can also facilitate the development of support for teacherdesigners in ways that work alongside, not against, their natural tendencies.

The context of this study is the design of curriculum-material for a technology-rich learning environment in Dutch kindergarten, named PictoPal. This learning environment for 4-5 year olds aims to foster understanding of the functions of written language. In PictoPal, pupils compose written documents on the computer and use these in off-computer classroom 
activities (e.g. grocery lists are 'used' in the store corner; recipes for 'cooking' are followed in the classroom play kitchen, letters to family are mailed, poems are read aloud at circle time; see Figure 1 for a screen capture of the on-computer activity). Previous studies in which teachers were involved during design and implementation of PictoPal material found learning gains in kindergartner understanding of the functions of written language (Cviko, McKenney, \& Voogt, 2011; McKenney \& Voogt, 2009). Teachers design the contents of the on-computer activities by specifying which written products children make, and the vocabulary words they will use to do so. Subsequently, the off-computer activities are also designed by teachers; these are as application activities in which children use their written products. Figure 2 is a screen shot of an off-computer activity. PictoPal preparation provides a context in which teachers design technology-rich material for early literacy development and therefore allows for studying teachers' explicated argumentation. The aim of this study is to understand how teachers naturally reason and what influences this reasoning during collaborative curriculum design.

- Insert figure 1 about here. -

\section{Literature review: Understanding design interactions}

Recently, scholars have investigated problem solving as reflected in the verbal interactions among teachers while discussing problems from their practice in so-called episodes of pedagogical reasoning (Horn, 2010; Little, 2002). In these types of conversations, teachers explicate reasoning by taking perspective, arguing for solutions and framing problems. Similarly, when making design decisions, reasoning is also explicated through talk. This explicated design reasoning provides a window for understanding design interactions. 
As shown in figure 2, the influences on design interactions can be clustered into three sets of factors: (a) existing orientations (knowledge, beliefs and practices); (b) external priorities (what priorities from external stakeholders have to be addressed), and (c) practical concerns (what is feasible and reachable in practice, how to orchestrate learning activity). The remainder of this section discusses each one, followed by the focus of the present study.

- Insert figure 2 about here -

\section{Existing orientations}

When teachers use, adapt, or (re)design curriculum material to fit their practice they make decisions based on (a) their practical knowledge - the personal knowledge base accumulated through experience in teaching and (b) their knowledge and beliefs related to how curriculum material is designed, adapted or used. In this study, TPACK is used as a framework to understand teachers' practical knowledge. Alone, pedagogy refers primarily to instructional strategies, classroom strategies and knowledge about learners, learning and teaching (Borko \& Putnam, 1996). Content knowledge (in the case of this study, early literacy) includes substantive structures (how ideas, concepts and facts are organized), syntactic structure (rules of evidence that guide inquiry in a discipline), facts, concepts and procedures (Grossman, 1990). Technological knowledge refers to a teachers' knowledge and beliefs about using technology in education (Koehler \& Mishra, 2005). Technological knowledge differs from the other knowledge domains and is best described as the ability to recognize the affordance of technology for educational purpose (Koehler \& Mishra, 2008). Emerging technologies are technological tools which are not considered ubiquitous and for which teachers have yet to identify their affordances for teaching specific subject matter in a specific context. TPACK as practical knowledge intertwines with the knowledge and beliefs 
about curriculum. Teachers often adapt curriculum materials to better fit their classroom practice (Davis, Beyer, Forbes, \& Stevens, 2011; Remillard, 2005). While such adaptations result from reasoning from their practical knowledge, teachers also use curriculum design knowledge (Remillard, 2005).

\section{External priorities}

Curriculum design does not happen in a vacuum. While existing orientations play an important role, (explicated) design reasoning is also influenced by priorities of stakeholders other than the teachers themselves. Such external priorities may be set by stakeholders on different levels varying from macro-level (e.g. national standards), publishers (e.g. textbooks) to the (near) school level, as expressed by school boards (e.g. local policy), principals or colleagues within communities of practice. For instance, subject matter content selections are often provided in curriculum material such as textbooks and software, which are designed by others than teachers themselves. Also, school boards or principals may set a variety of priorities, for instance about the kind of education. When designing, these external priorities often focus and/or limit teachers' choices. In kindergarten, external priorities might for instance be: developmentally appropriate practices in teaching and learning, appropriate practices in computer use by young children, early-literacy content knowledge, and policies (Buchanan, Burts, Bidner, White, \& Charlesworth, 1998; Stipek \& Byler, 1997; Turbill, 2001). These external priorities are often implicitly embedded in the organizational context in which teachers work.

\section{Practical concerns}

Lesson planning, curriculum design and instruction are influenced more by considerations concerning concrete classroom activity than by abstract subject-matter knowledge or learning goals (Handelzalts, 2009; Kerr, 1981). Teachers' (explicated) 
reasoning reflects their practical concerns as contingencies and limitations in classroom practice. Found in literature, the most salient are: (a) organizational issues ('how much time is available, how are students seated, what classroom do I have available')(de Kock, Sleegers, \& Voeten, 2005); (b) relationship between student and activity (how will students react to this, what will students do with it) (Deketelaere, 1996; George \& Lubben, 2002; Parke \& Coble, 1997); or (c) how subject-matter is presented to students in such a way that it becomes feasible in practice (Handelzalts, 2009).

\section{Focus of the study}

This study was designed to examine how design interactions in teacher teams demonstrate explicated reasoning from existing orientations, external priorities or practical concerns during the design of PictoPal material. This is important because the design interactions of teachers involved in collaborative curriculum design are hardly studied. The insights from this investigation help to better understand design processes in teacher teams and are needed in order to provide adequate support to teachers during the obviously complicated task of designing curriculum material. In order to understand what drives teacher decision-making when designing curriculum, this study first investigated the existing orientations that the teachers held on technology, pedagogy, early literacy and curriculum design. Thereafter, the study examined teachers' actual design interactions. After portraying these, further analyses were conducted to discern the kinds of factors that most powerfully influenced their design interactions. In this study, answers were sought to four questions:

- RQ1: What are the teacher design teams' existing orientations regarding technology, pedagogy and early-literacy? 
- RQ2: What are teacher design teams' existing orientations regarding curriculum design?

- RQ3: What do the teacher design team interactions look like?

- RQ4: When designing, what kind of argumentation underpins the decisions in the design team?

\section{Methods}

\section{Design and participants}

A multiple holistic case-study approach was applied in this study, with design team conversations as unit of analysis. In this study, teachers participated voluntarily, responding to an open call distributed among all kindergarten teachers in an urban area of the Netherlands, and expressing interest in designing a learning environment for early literacy. From two different schools, two teams of kindergarten teachers participated (Team A: N=4; Team B: $N=2$ ). Also responding to the open call were two teachers who had more early literacy expertise through in-service education and another teacher with early-literacy and technology expertise who gave in-service teacher training. Thus, an additional team (Team C) of three language experts was formed, allowing for a contrasting analysis of design interactions. Comparisons in this study are made between the design interactions of regular kindergarten teachers and those of teachers with extended expertise in early literacy. In Table 1 , an overview of the teams and background information of the teachers is presented.

- Insert table 1 about here -

\section{Data collection}

At the start of the study, using a semi-structured interview, inquiries were made about partcipants' existing orientations (knowledge / beliefs and self-perceived competency in 
technology, pedagogy, early literacy, curriculum design). The interviews were recorded and transcribed. A few weeks later, teachers attended a design workshop in which they designed Pictopal learning activities. To familiarize teachers with the program, a video was presented featuring example PictoPal learning activities. After this short introduction, the assignment was given: "Design a set of PictoPal on- and off-computer learning activities." Any questions to clarify the assignment were answered, and discussion in the teams quickly commenced, signaling the start of the design. To ensure that the deliberations of teachers were as authentic as possible, several measures were taken: (1) support was kept to a minimum; (2) only when teachers specifically addressed the researcher on matters that were unclear, was a response provided; and (3) teachers were also free to discuss any topics that they deemed relevant. The deliberations of the teachers were videotaped and transcribed; video aided in identifying which participant was talking (names in findings section are pseudonyms).

\section{Semi-structured interview}

The semi-structured interview took approximately one hour for each teacher, resulting in nine interviews in total. Teachers were asked to respond to a sequence of questions stemming from: 'What are your beliefs regarding...?' and 'Can you provide classroom examples?' This sequence was repeated within each domain: technology, pedagogy and early literacy.

To answer the second research question, we asked teachers questions regarding curriculum material design and use: 'What is your experience in designing material?', 'How do you use formal curriculum material in kindergarten?', 'How competent do you feel you are, and what type of support do you need, when designing curriculum material?', 'Who should be responsible for curriculum design: teachers, educational designers, both or someone else and why?' 


\section{Data analysis}

The following procedure was used to analyze the data of the semi-structured interviews on teachers' existing orientations: (1) The written transcripts were read several times, fragments in the written transcripts were selected that conveyed teachers' existing orientations regarding technology, pedagogy, early literacy, or curriculum-material design and use; these fragments were coded. (2) Each fragment was summarized and a categorycode (descriptive) was added (Table 2 provides an overview of the domain and category codes). (3) For each team, a matrix was constructed with individual team members on the xaxis and categories found on the y-axis; this was aimed at gaining better understanding of knowledge, beliefs and practices that individual team members brought to the deliberations during collaborative curriculum design. (4) The quotes representing these orientations were summarized as statements that reflected either knowledge / beliefs or practices. (5) Constant comparison (Strauss \& Corbin, 1998) was applied on the quotes. This allowed for several themes within each domain to emerge, depicting how and whether or not at the team level differences were present. Quote summaries aided in this refinement of codes as it prestructured our analysis, yet constant comparison was conducted on the original quote. The first author conducted initial coding, the themes and categories were discussed with the other two authors resulting in a refinement of the codes. A researcher who was not involved in this study independently coded $10 \%$ of three interviews (descriptive), inter-coder reliability was calculated as acceptable (Cohen's Kappa $=.69)$.

- Insert Table 2 about here - 


\section{Analysis of design talk}

The analysis of the design talk occurred on the written transcripts. These were in Dutch since all participating teachers were working in the Netherlands, (and the researchers were also fluent in Dutch). Selected quotations were translated when writing this article. Design talk was analyzed by classifying the interactions into categories. Although various models for curriculum design might also bear consideration for developing a new coding scheme for the analysis of design talk (see for instance Stenhouse, 1975), this study made use of an existing coding scheme, the SACD (Walker, 1971), that has been successfully used to portray educational design conversations. Walker, (1971) developed and used the SACD to code design talk in three subject-matter oriented, curriculum development projects. Shown in Table 3, the SACD was taken as the starting point for this study; it provides codes on the levels of episodes as well as moves (single-utterances). However, the analysis that Walker conducted while conceptualizing the categories of the SACD was limited to reporting frequencies of codes only. The analysis in this study was also qualitative, portraying how explicated reasoning occurred through argumentation. The arguments that are portrayed therefore pertain to the three kinds of explicated design reasoning described previously.

- Insert Table 3 about here -

First, to gain a general portrayal of design team interactions, the entire discussion was segmented in episodes, which according to Walker (1971) is 'a consecutive portion of transcript having a degree of unity and coherence and being separable from the surrounding discourse by subject and style of discussion.' (p. 112). Following Walkers' SACD, these were coded as one of four types: brainstorm, issue, explication or report. During a brainstorm, ideas are generated, interaction is high and decisions are taken intuitively. During 
an issue, a problem is identified, framed and its' solution is debated; decision making is highly argumentative. In an explication, one person talks, lectures or provides insights on a topic or subject of which he or she has exclusive knowledge. Finally, a report, for instance reflects a concrete classroom example as an illustration.

Second, in each episode, the nature of the deliberation was analyzed by marking portions in the episode in which decisions are explicated in the conversation. Open coding was applied by summarizing these decisions on what aspects of the material were decided upon (for instance learning activity, classroom organization). Keeping an open mind, such decisions might occur in all four types of episodes; but the expectation was that coded as issues would contain most of the explicated argumentation, while for instance brainstorm argumentation would be more tacit and implicit. The analysis of the argumentation therefore was conducted on the episodes that reflect pivotal decisions, steering the course of the conversation and in which argumentation is explicated and thus, visible in transcripts.

Within each of these selected episodes, single utterances that reflected teachers' individual contributions to the conversation, individual deliberative moves were coded using the SACD as one of four types: problem, proposal, consideration, or instance. A problem is a statement that frames an unsatisfactory situation or a part of the design that needs the groups attention; a proposal reflects a solution to the problem; a consideration is made for or against a proposal; and an instance is an illustrative remark. Short remarks such as 'yes' or 'well' were not coded.

Since explicated design reasoning occurred through argumentation, the moves were also coded for explicated design reasoning. This was done by coding each move as pertaining to either existing orientations, external priorities or practical concerns. Existing orientations reflect teachers' personal knowledge base in the argument; external priorities reflect an 
argument of a stakeholder other than the teachers themselves; and practical concerns relate to organizational aspects of the design.

A researcher (also a Dutch native speaker) who was not involved in this researchproject independently coded a sequence of 400 single utterances (first on the level of episodes then by coding moves). This constitutes approximately $20 \%$ of the overall data set. Intercoder reliability was calculated, procuring satisfactory levels of reliability (Episodes, Cohen's Kappa $=.70$; Moves, Cohen’s Kappa $=.71)$.

\section{Findings}

\section{RQ1: What are teacher design teams' existing orientations regarding technology, pedagogy and early-literacy?}

While investigating existing orientations towards technology, pedagogy and design, teachers responded by providing examples as well as rules. Themes within each domain emerged during interpretative analysis of the categories and subcategories. The team-specific findings are discussed in light of overarching themes.

\section{Technology}

Technology is addressed through a pedagogical frame of reference

Team A: Teachers in Team A preferred to use computers individually and with the purpose of providing an extra activity. Dany provided a practical reason: "You should use computers individually; otherwise it just is not feasible." These teachers expressed that computers were just part of the array of other learning material available in their classroom. All teachers believed that computers were appropriate. Although positive, Gretha reflected: 
"Kindergartners learn mostly by concrete activity" (Tech-Ped-Learner). The other teachers did not mention such concerns, one of them stated: "[Technologies] are there, so you just have make best use of them" (Tech-Ped-Instr).

Team B: Besides providing examples of practice in individual use, the two teachers in this team also provided examples of how they used the computer in collaborative settings. Also, these teachers believed that computers were appropriate in kindergarten. One of the teachers was enthusiastic about computers and even mentioned that she took time to teach kindergartners computer skills.

Team C: There were differences regarding how the teachers portrayed their existing orientations regarding technology in Team C. Similar to team A, Ally stated: “A computer is just extra, children get their instruction foremost from regular teaching” (Tech-Ped-LLT). However, both Trinny and Arya talked about affordances of computers in terms of what the added value was on childrens' learning. Trinny, reflected on the affordance of computers on collaborative learning, she also stated that computers are smart tools providing structure, monitoring childrens' progression, unlimited patience and a tool for monitoring a childs' progression. Furthermore, Trinny explained the rationale behind a computer program for early literacy that she designed and formed the basis of her training to in-service teachers. Arya, an early literacy expert from a school of special educational needs kindergartners, mentioned computers in light of early literacy in her school context, stating: "When a computer program does not present written words as accompaniment to spoken words, we refrain from using that program. Research has pointed to the importance of this."

Teachers view computers as a tool for early literacy learning activity.

Team A, B: Teachers in both teams talked about practices that involved children typing letters or words on a computer. Teachers from Team A stated that they occasionally 
used the Interactive Whiteboard (IWB) to display a digital storybook or show a video fragment for illustrative purposes. Teachers from Team B only expressed using digital storybooks for children to be read individually.

Team C: Differences were found within the knowledge and beliefs of this team. While digital storybooks were mentioned by both Alice and Arya, Trinny referred to how she believed technology afforded for development of reading skills in children who had difficulty reading. As mentioned earlier, she had a wealth of experience in designing technology for early literacy, and to date still provides lecturing on this topic to in-service teachers. Trinny explained in detail why and how to use a computer. Similarly, Arya had ample experience in in-service support of teachers at her school regarding early literacy and provided a wealth of examples, also in regard to her use of technology. For instance she showed and demonstrated a keyboard with audio support (single letters were spoken aloud) and discussed practices in which she used those. 


\section{Pedagogy}

Teachers direct their teaching behavior mainly to develop kindergartners socio-emotional well-being.

Team A: Teachers from Team A discussed beliefs about how to develop childrens' socio emotional development through teacher-child interaction. For example, Ann stated: "Approach a child with a positive attitude (Ped-LLT)." One teacher in this team furthermore mentioned that socio-emotional development is one of the important areas in which a child develops in kindergarten. Furthermore, Team A teachers expressed the importance of a positive atmosphere because children in kindergarten mostly develop their socio-emotional wellbeing.

Team B: Similar to Team A, these teachers expressed their beliefs regarding the behavior of a kindergarten teacher. Beliefs regarding how kindergartners learn were reflected in teachers' responses; Erin for instance stated: "If children go home feeling bad, the consequences are rather serious" (Ped-LLT). Furthermore, these teachers stated that teachers should provide environments of safety and trust to develop their general aptitude. Annette expounded her opinion that modern-day kindergartners grow up in a demanding society, one that rushes the development of children. She stated that a child should be given the time to develop instead of being pushed forward to academic development.

Team C: Knowledge and beliefs about creating a positive teacher-child relationship and striving for a positive climate were expressed by the regular teacher in this team. Ally stated: "Commemorate a child's good behavior, this reinforces a child's sense of selfefficacy" (Ped-LLT). She also pointed out that "even if you have given a child a scolding, always maintain a good relationship afterwards." The other two teachers did not address 
socio-emotional development of kindergartners, rather they discussed instructional strategies in kindergarten.

Teachers express how they motivate children as the most important strategy for teaching and learning in kindergarten

Team A and B: Regular kindergarten teachers expressed knowledge and beliefs regarding how kindergartners learn. In Team A, these beliefs were mainly expressed in terms of ' what a teacher has to do to...'. Two comments from Gretha (Team A) reflect this: "Motivate children by using concrete material (Ped-LLT)", "Adjust your language to a developmentally appropriate level (Ped-LLT)". However, the topics discussed mostly concerned classroom management-related topics. Teachers from Team A and Team B expressed a large number of pedagogical approaches to kindergarten education and how to organize them: circle-time, small-group instruction for remediation or focused instruction, peer-collaboration and working in small groups on a particular learning task. However, teachers from Team A also were focused on how to organize the flow of activities in a kindergarten classroom. Teacher Dany (Team A) mentions: "I am a big fan of structure" (Ped-Classr) also her colleagues discuss the importance of teaching children classroom rules. These teachers furthermore stress that it is important to show predictable teaching behavior, so that children will get used to the routine.

Team C: Both Trinny and Arya first stated that they had no actual teaching experience in kindergarten classrooms. Yet both of them expressed that children learned through engagement in authentic and meaningful activity. Ally however mentioned how she organized a number of the learning activities that the teachers in Team A and Team B mentioned. Ally focused mainly on explicating beliefs and knowledge about socio-emotional 
development of kindergartners and the importance for teachers to have improvisation skills. These were needed to adequately respond to unforeseen events.

\section{Early literacy}

Regular teachers discuss learning activities and why it is important to learn how to read; language experts also explain why.

Team A: teachers discuss early-literacy concepts as classroom activity, expressing what they do in their classroom such as book reading, rhyming, doing letter-sound exercises and exercises to develop children's vocabulary. Marla expressed the concept of phonemic awareness (recognizing separate sounds in a word), yet in terms of the activities that children do: "If children have problems with 'cutting and pasting' they will have problems reading (EL-Conc). Teachers of this team conceptualized early literacy in their statements as the ongoing development of reading that starts before the onset of kindergarten and is important for kindergartners because it prepares them to function in a modern society.

Team B: Teachers in Team B stated that they were very attentive to early signs of deficit in children's vocabulary when they entered kindergarten. Annette reflects: "When a child enters my classroom the first thing I do is talk, just to understand his vocabulary level" (EL-Conc). Annette reasoned that a poor initial vocabulary impeded further development in literacy. Similar to Team A, these teachers specifically stated that the purpose of early literacy was to function in society.

Team C: Ally's responses resembled those from the other regular teachers. She stated what kind of activities she conducted, book reading and whole class exercises that develop phonemic awareness. In contrast, Arya used a storytelling table to have children reenact the scene of a book and use of cards with written words and pictures to enhance phonemic awareness. As her area of expertise was the individual instruction to children with learning 
disabilities, she did not mention any whole class activities. Arya, however provided rules-ofthumb for the specific learning activities, while the other teachers did not. Trinny did not mention specific concepts in early literacy.

Instructional practice in early literacy is ad-hoc, unplanned and reflects strategies for motivation to discover early literacy

Team A: Fueling curiosity was a preferred instructional strategy, to allow kindergartners to make explorations and discoveries about literacy. Gretha reflects: "Use childrens' own interests." Teacher Dany furthermore reflects: "It is not like we plan an early literacy activity, we do this throughout the entire day" (EL-Strat).

Team B: These teachers stated that whenever they had the opportunity, they addressed children's early literacy development through reading, rhyming games or activities on phonemic awareness. Erna: "So for instance you seize every opportunity, like 'tie your shoelaces', or 'who has the same letter in his name..." (EL-Strat). Furthermore these teachers agreed that early literacy develops mostly through discovery, they learn to recognize what reading entails, they mostly 'feel' by being engaged. In this light, Erin stated: "Provide all kinds of learning activities, even if they do not understand it will still be meaningful to them" (El-Strat).

Team C: Trinny discussed what she found appropriate to address as a teacher in order to develop early literacy. She also mentioned the importance of motivating children to get an interest in reading, yet she emphasized that: "If a child is interested in reading, don't let him write letters! Instead, teach him to recognize the basic letter sounds like 's', 'm' and 'v', and soon he will read simple words" (EL-Strat). Furthermore she believed that early literacy development should only be addressed to when a child showed interest in reading. Trinny also believed that the single goal of early literacy development "only involves recognizing 
sounds that letters represent" (EL-Strat). Ally and Arya did not discuss such beliefs, they discussed the various activities and how to motivate children to get involved an interested in early literacy.

Perceived competencies in the three domains: technology, pedagogy and early literacy

All teachers felt competent in the domain of pedagogy and did not state they needed support in this domain. In the domain of technology, one teacher stated that she lacked skills in technology-use and welcomed an opportunity to learn new ways of how to manage technology in her classroom; the other teachers felt skilled enough, yet welcomed new ideas on classroom management. In the domain of early literacy, all teachers found they had sufficient skills, but again welcomed an opportunity to expand their knowledge of learning activities. The language expert teachers also welcomed the opportunity to expand their knowledge on early literacy.

\section{RQ2: What are teacher design teams existing orientations regarding curriculum} design?

When designing curriculum material or adapting existing material, learning goals that teachers themselves set, direct teacher decisions.

Team A: Teachers from Team A stated that they used a self-designed curriculum framework, which consisted of goals to be attained in kindergarten for several domains. Teachers mentioned the use of textbooks and teacher guides as inspiration for designing their own classroom activities. Gretha from Team A stated: "We don't use material like they do in the upper-grades, we have more freedom to do as we see fit." Teachers from Team A all were convinced that they were capable of designing technology-rich learning material and welcomed input from technology experts and early literacy experts. 
Team B: Teachers from Team B relied on their own experience when designing curriculum material. They used curriculum material to inspire their lessons, but were used to designing their own lessons. Furthermore, these teachers found themselves competent in using and designing material, but also stated that cooperation from technology experts and language experts could provide them with specific knowledge during design of such material.

Team C: The teachers from Team $\mathrm{C}$ also relied on their own experiences, yet showed variation: Arya used standards and learning goals set by Dutch policymakers in early-literacy education, Alex used her experience in teaching in kindergartens and stated that in her school, the learning goals set by the Dutch government guided teachers in designing learning activities. Also, Alex (Team C) stated the importance of such an approach to curriculum material use in her school: "In our school, it is very common to 'let go' of the formal educational material, and design our own learning activities. We, as kindergarten teachers are very skilled at that, and we would also like to see this approach in the upper grades of our school" (Curr - insp).

\section{RQ3: What does design interaction look like?}

This question focused on the macro-level analysis of how the conversations were organized in episodes, as either brainstorm, issue, explication or report. Tables for each team show how many utterances one episode consisted of, the code that was attached to this episode, the episode-number and the total number of utterances for each type of episode. For reading comprehension, the findings are presented as a narrative in which the sequence and the topics of the episode are discussed; the tables serve an illustrative purpose. In the tables, B stands for Brainstorm, E for Explication, I for Issue and R for Report. 


\section{Team A's design interactions}

Team A's first comment was that PictoPal - in its' current state - did not appeal to them, so they decided to formulate their own design task which was: build an on-computer activity with more freedom for children to express their own story. During the first episode, teachers brainstormed about the type of learning activity. This triggered an issue episode in which, with the topic of children's' unanticipated actions while conducting the learning activity. What followed was a report in which one teacher shared her experience in allowing children to write their own story, upon agreement the teachers initiated a brainstorm session to further design the contents of the computer program such as lay-out, pictures and words.

As can be seen in Table 4, two episodes were coded as issues. In the first (episode 2), teachers discussed the problem that would occur when children wanted to choose a word from that was not available in the limited list. This issue was introduced by Dany. The issue was only discussed shortly, and no apparent decision or solution was discussed. Rather the conversation just evolved into teacher Ann's explication of her experience with a learning activity that also allowed children to write their own 'work'. The second issue (episode 5) pertained to the issue that was raised in episode 2. Episode 5 was followed by a brainstorm, in which the contents of the computer program were discussed. Issue 7 marked an interruption in the brainstorm; one teacher still was not convinced that the current design allowed children to express themselves. When this issue was resolved, the design session ended with two brainstorm episodes. Episodes 8 and 9 were on finalizing the design and rounding up the deliberations. Note the large number of brainstorm episodes $(n=5 ;$ total $n=9)$ and the large number of interactions ( $\mathrm{n}=384$; total 455 making up 84,4\%) found in brainstorm episodes 6 and 8 . In contrast, the total interactions devoted to issue episodes made for only $7,3 \%$. 
- Insert Table 4 about here -

\section{Team B's design interactions}

As shown in Table 8, Team B's teachers were curious about how the program functions, and after showing them the functionality, they started brainstorming on activities and content. There were five brainstorm episodes, of which two exceeded the other episodes in length considerably. After brainstorming on what type of activity students would perform and how the program should function, one teacher mentioned that she was unsure whether children would understand that in the program, words are represented by pictograms. After several short episodes of issue, the teacher (Gretha) was finally convinced, especially when witnessing what the program actually looked like on paper. During a short explication episode, she stated that the functionality of the program resembled curriculum material that she had used. After this episode, four brainstorm episodes occurred in which the contents and the functionality of the program were designed. Similar to Team A, the number of total utterances for brainstorm issues was large: 329 of a total of 379 ; a percentage of $86,8 \%$.

- Insert Table 5 about here. -

\section{Team C's design interactions}

Team C's teachers discussed the ideas behind PictoPal first (see Table 9), and thereby framing their own convictions on what kind of early-literacy practice they personally found important. They did so in the context of PictoPal, explaining why a certain conviction was so important and how it could be incorporated in the design of the learning activity and content. One of the participating teachers (Trinny) was an early literacy and technology expert who currently was employed as a teacher trainer. She explicated her view on what kind of content and activity would be most appropriate and that software could be programmed in such a way 
that it did not allow children to make erroneous decisions. Following was a short series of issue episodes in which the content of the learning activity and program were discussed, which then indicated that the program contents were designed during a brainstorm episode. Again, the number of single utterances that pertained brainstorm was large: 310 of a total of 398 utterances; a percentage of 77,9\%. However in contrast to Team A and Team B, the utterances devoted to discussing issues was larger: $12,3 \%$.

- Insert Table 6 about here -

Summarizing, all three analyses of design talk provide a picture of the design interaction as that of being a steady stream of ideas generated, occasionally interrupted by short issues in which a problem is briefly discussed. Comparing design talk among the three teams, reveals differences in how the design is initiated: the two teams of regular kindergarten teachers initiate a brainstorm on the contents of the learning material and on the learning activity, while the team of expert teachers (Team C) initiates an explication episode in which Trinny expressed her view on early literacy education. Yet before the first issue episode, Team $\mathrm{C}$ also initiated a brief brainstorm on the learning activity. The design interaction of all three design-teams ended with a brainstorm in which teachers appraised the material and came to closure of the design workshop. 


\section{RQ4: When designing, what kind of argumentation underlies the decisions in the design}

team?

This section presents the findings of the analysis on design talk on the level of utterances in episodes in which argumentation was explicated. The previous section showed that brainstorm episodes are initiated to generate ideas and no argumentation is present. Therefore these episodes do not reflect explicated reasoning. In issue episodes, argumentation is visible in the conversation, reasoning is explicated: hence only the episodes that were coded as issues were selected to be coded on the level of single utterances. For each team, one figure presents the sequence of coded utterances within each selected episode.

For each coded utterance, an argument code is applied where 1 stands for practical concern, 2 stands for existing orientation and 3 stands for external priority. Furthermore, each utterance that is marked as a large circle pertains to a problem statement.

Analysis on design talk on the level of deliberative moves in Team A

Figure 3 shows three selected episodes of Team A's conversation: six problems were discussed, two reflected existing orientations; the response to these two problem-statements was a proposal reflecting a practical solution. In issue 1, the second problem statement was made by teacher Dany, who also initiated the issue episode, which reflected an argument from practice (“....or children might choose to write about a pirate who wants to become a knight"). Issue 1 is not resolved. Rather, utterance 11 (Marla), initiates the second episode, which was a report on her experience in using children's' own stories. This shows that the solution is not explicated as such. Rather it occurs by skipping ahead. Issue 2 is initiated by Gretha who still feels that the first issue is left unresolved, her statement therefore also reflects her existing orientation ("I still have a problem, how do we... children, who want a 
word that is not incorporated"). The other teachers respond by making several proposals, yet Dany brings up the problem that the proposals might lead to a program that cannot be used without the teacher's help, however more proposals follow that reflect how content is organized in such a way that the problem does not occur. Utterance 47 was coded as a consideration, which reflects the argument that children do not use complicated sentences. The final problem (Gretha) in Issue 2, pertains to the concern that young children might misinterpret the words. Anny responds that this is not a problem, yet an opportunity to learn. Issue 2's final utterance initiates the brainstorm, signaling the end of issue 2 ("ok, what else can we come up with?"). The lengthy brainstorm is abruptly stopped by Gretha's comment on the on-computer activity: "I think it is a rather large number of steps!" As shown in figure 3, this proposal is met with various remarks, yet Gretha persists and states: “. . but you are, first you have been doing...”, this last statement is met with “.. but nowadays, children are good at using computers. It doesn't all go that slow anymore," (Anny). This statement reflects an argument from the existing orientation. Subsequently, various proposals are made, of which Gretha makes one: "Ok, so the words are directly linked to... that's what I mean!" Upon mutual agreement, the final brainstorm episodes were initiated.

- Insert figure 3 about here - 
Analysis of design talk on the level of deliberative moves in Team B

Figure 4 shows that Team B discussed 5 problems, 2 of which reflect arguments from existing orientations. In the first problem statement, Annette questions whether children understand that pictograms substitute words. As can be seen in iFgure 3, issue 1 is the second episode in the conversation, and comes right after the brainstorm episode. Furthermore, issue 1 is mostly discussed through remarks that reflect arguments from practice.

Utterance 120 marks a pivoting point, Annette recalls a piece of the video on PictoPal that was shown at the start of the workshop: "The fun thing is, in that piece of video you see a teacher reading a text, and the child becomes enthusiastic! Like, wow, my work gets printed it has sounds and words." This remark furthermore shows that Annette gets motivated. Erica furthermore comments on this remark by stating how she sees functional literacy (children making discoveries about written language). The final remark of Erica shows how PictoPal affords this.

Following are three short episodes in which the problem in issue 1 is further resolved. Figure three shows that in issue 3 and 4 three problems were addressed, all of which reflected practical arguments. The conversation then continues with an explication, followed by four brainstorm episodes.

- Insert figure 4 about here. 
Analysis of design talk on the level of deliberative moves in team $C$

Figure 5 shows that 6 problems were discussed in Team C's conversation, all of which were coded as existing orientations. Figure 4 furthermore shows that the arguments that follow these problem statements, (in issues 1 and 2) mostly reflect existing orientations, while in issue 5, arguments reflect practical concerns.

Issue 1 is started when Arya states the problem: "Words like 'give' and 'may' are difficult to draw pictograms for..." (one of PictoPal's on-computer features is that words are shown on a button with a pictogram so that children who cannot read understand this word). The solution is to limit the number of words, but also to use simple words. Trinny advocates the following solution: “... it is better to have children discuss a situation, like "the cat lies in the basket,' and then illustrate what they see, in order to visualize the meaning of this situation." However, Arya's response is that simple sentences like "the cat eats fish", do not reflect how children would say it (initiating problem statement in issue 3). Alice's response reflects agreement with Arya: “and.. it's not a challenge for children... don't you want a child to say 'Wow, now I've got something!?” Arya responds by illustrating a classroom situation in which one child hides a toy cat, and in PictoPal a simple letter is produced communicating the location of the toy cat.

Trinny's response (initiating issue 5), is that such a task is to complicated: telling a story is difficult, let alone producing a written story, that has to be communicated in front of a group of children. Alice, however states that such a task can be performed when children are supported by: “...first simple and then the next step, one word extra." This is confirmed by Arya, and the issue seems resolved.

- Insert figure 5 about here. - 
Throughout all three conversations, a similar pattern emerges in which initially problems are framed from teachers existing orientations regarding how kindergartners learn and will react to the material, while later after having brainstormed about the specific content of the learning activity and the PictoPal computer program, problems emerge that relate more to practical concerns. A recurring theme related to teachers existing orientations that appeared to influence design talk was motivation strategies. The findings on the existing orientations show that teachers believe that children are motivated by performing activities that adults do (e.g. thorough play corners) and that both entail and enhance their understanding of the world. During the design conversations, motivational strategies are discussed by all three teams. Team A questions the motivational strategy embedded in PictoPal and designs their own learning activity that would enhance motivation. Team B also discusses that, when a teacher reads a text written by a child out loud, this could foster enthusiasm for literacy. Team $\mathrm{C}$ questions whether easy sentences could convey messages that would relate to childrens' interests.

Across the teams, differences in argumentation were identified. The language experts regarded technology from an early literacy education view. That is, they mentioned specific early literacy learning strategies. Regular teachers regarded technology from a pedagogy view. That is, they discussed general pedagogical strategies most. These differences also occured when comparing conversations of language expert teachers and regular kindergarten teachers. There were no notable differences between the two regular teacher teams.

\section{Conclusions and discussion}

This study explored collaborative curriculum design in two teams of regular kindergarten teachers and one team of early literacy expert teachers, designing learning material to be used in a technology-rich learning environment for early literacy. The goal was 
to understand whether and how teachers' existing orientations, external priorities and/or practical concerns influenced their conversations and decision-making. To achieve this aim, teachers existing orientations on technology, pedagogy, early literacy and curriculum design were first examined. Next, design talk was analyzed to portray if and how existing orientations, external priorities and/or practical concerns were reflected in the conversations. Differences as well as similarities were found in how two types of teachers (regular and early literacy expert) expressed these orientations. For kindergarten teachers, technology is addressed through a pedagogical frame of reference, how it is used for learning. Occasionally they provided practices, generic ways of using technology and more specifically how they use computers for various writing and reading activities. Early literacy experts discussed technology from a pedagogical frame of reference but also from an early literacy frame of reference. Similarly, both the regular teachers and early literacy experts expressed knowledge and beliefs about teaching and learning in kindergarten: motivational strategies, socioemotional development and how kindergartners learn. Motivational strategies however also seemed to influence teaching strategies in regard to early literacy. Motivation according to both types of teachers, is achieved by providing authentic tasks, learning activities that would appeal to kindergartners.

While literature suggests that curriculum design is influenced by TPACK, the existing orientations that teachers have in relationship to curriculum design are understood less well (Remillard, 2005). Findings from teachers' existing orientations on curriculum design show that teachers use their own experience as a resource for inspiration to design learning activities for kindergartners. This finding is in line with the study on design practice by elementary schoolteachers by Beyer et al. (2011). The findings of this study suggest that what a teacher knows about teaching and learning influences the goals that a teacher sets and 
thereby also calls into memory the kinds of activities that a teacher knows would work to achieve these goals.

The findings of this study are consistent with literature on design cognition, the kind of thinking involved when 'designing'. The finding that existing orientations play an important role is similar to Lawson's (2004) discussion of precedent, which is a designers ability to recognize a class of problem and use previous experiences to think in terms of concrete images to solve these problems. This could imply that when material is being designed or adapted, teachers first draw on existing understanding about how children learn and the related instructional strategies and practices that they have accumulated through experience.

The findings of the analysis on design talk on the level of episodes suggests that designing is predominantly a brainstorm process; most episodes were coded as brainstorm, most brainstorms were also very long in duration. The approach to collaborative curriculum design resembles a solution-driven approach to solving design problems (Hong \& Choi, 2011), in which designers quickly generate solutions. The problem does not get analyzed in depth before generating these solutions. Rather a designer gradually unravels the problem as solutions are tried and discussed. In this approach, the problem and solution are defined together (Cross, 2004). Consistently, this study's findings show a pattern in which first a tentative solution gets brainstormed, followed by one or more episodes in which an issue is discussed, followed by one or more sessions of brainstorm. Occasionally these brainstorms are 'interrupted' by small issue episodes. However the general impression of the conversation in these latter stages of the design process are more about brainstorming. Teachers, in this study are prone to skip an analysis of the problem. Though as Lera (1981) noted, the term 'analysis' in design is often more a process of testing conjectures. 
Although often viewed as naïve and intuitive, such limited problem analysis has been used by successful expert designers (Cross, 2004). As such, this study cautiously gives reason to challenge the claim that teachers' design approach is unsystematic (Hoogveld, Paas, \& Jochems, 2003). The design approach of teachers can hardly be represented by instructional design (ID) models or other system design models (Rapanta, Maina, Lotz, \& Bacchelli, 2013). Important decisions are made when teachers encounter a problem. It is fruitful to gain a detailed process understanding of how such problems get addressed through conversation.

In this paper, the micro-level analysis of design talk focused on issue episodes, which provide better understanding of the moments in conversation in which important decisions are made. These issue episodes also reflect explicated reasoning through argumentation. During brainstorm episodes, argumentation is lacking as teachers provide no reasons for their decisions. The findings of this study on the micro-level found an interesting pattern emerging. Problem statements that occur at the start of the conversation reflect existing orientations; problem statements further down the conversation reflect practical concerns. Furthermore, argumentation through proposal reflected more practical concerns when analyzing the conversations of both teams of regular teachers. In the conversation of Team $\mathrm{C}$, argumentation through proposing and explicating considerations continued to reflect more of their existing orientations. Though it should be noted that the last issue episode reflected more of their practical concerns. External priorities were hardly discussed by any team.

The findings of this study suggest that teachers' intuitive approaches to design can be characterized as gaining an understanding of the design problem by reaching early solutions and changing the solutions as they go. Gradually their understanding of the design problem evolves as the material is brought to life through talk. As an image of the problem (and solution) takes shape, a collaborative problem space (Jonassen, 2000) emerges. Gradually, by explicating their existing orientations to define problems of these early solutions, they reach 
an agreement. In this study, the early solution is furthermore shaped by existing orientations that reflect what a teacher knows and believes about motivational strategies for early literacy development. These are translated into technological solutions. These strategies are then discussed, practical concerns are addressed, and problems may again emerge. These problems also reflect mostly practical concerns, yet solutions made earlier in the design are being processed and brought to life through brainstorming.

This study suggests that teachers existing orientations serve as precedent (Lawson, 2004), to help teachers recognize the design problem and find solutions that seem trusted and feasible. Strikingly, when existing orientations to teaching and learning are explicated during design conversations, for all three teams, these somehow pertained to the concept of motivation. Questions are asked such as: "Does this activity motivate children?"; "How to make sure that kindergartners are motivated?" So while teachers discuss the problem, their early solution tends to be meet this single criterion and is not subject to critical discussion after the solution has been tentatively agreed upon.

Several reasons can be found, however this has mostly to do with the 'wicked' and complex nature of design problems (Rittel \& Webber, 1973). According to Jonassen (2012) design is often considered a form of complex problem solving, involving a great number of decisions. Decisions are typically the result of judgment, which may be deliberate off-hand judgment (in which novel design-problems trigger designers explication of the decisions they make and why they made these decisions) or default judgment which occurs almost spontaneously and is tacit (Nelson \& Stolterman, 2012). In this study, teachers' deliberate off-hand judgments became visible when they disagreed. Thereafter, teacher discussion drew on experiences in teaching in kindergarten, their existing orientations (especially regarding motivational strategies for early literacy) and practical concerns. The emphasis on practical concerns (how do we organize this, what do children actually do) is consistent with the 
teacher practicality ethic (Doyle \& Ponder, 1977), which states that determining whether or not to adopt a new innovation involves processes that appraise an innovations' (a) instrumentality (does the innovation specify what I as a teacher should do); (b) congruence (do I agree with the innovation) and (c) cost (how much of my effort will it require).

\section{Limitations}

The findings of this study must be considered in light of its limitations. First, only three teams were studied, which limits the generalizability of the findings. Future studies could apply the data collection and analysis methods to other contexts, investigating whether the emerging patterns in design talk also emerge when teachers of other types of education collaboratively design curriculum material. Second, only two data sources were used. Future studies could, for instance by stimulated recall, invite teachers to explicate their reasoning, which would then be compared and contrasted with the findings of the interview on existing orientations and the actual design talk. This could lead to a more comprehensive understanding of teachers' curriculum design reasoning. Third, the difference in argumentation (RQ 4) that was found between regular kindergarten teachers and language expert teachers might not originate from a difference in knowledge and beliefs on early literacy. The team of language expert teachers had never met before, which might have triggered constructive conflict, and conversations in which more argumentation occurred. In a similar vein, since the regular teachers knew each other already, it is possible that some reasons were not explicated because they were regarded as mutually shared understandings.

\section{Implications}

The findings of this study have both theoretical and practical implications. While research on 'how designers think' has been substantial (e.g. Cross, 1982; Dorst \& Cross, 2001; Stempfle \& Badke-Schaub, 2002) the attempt to unpack design thinking as well as 
explicated reasoning in teacher team design talk is fairly novel. Prior studies on the design processes that teachers conduct in design teams have focused on outcome variables and tend to be very abstract. This study suggests that an important dimension is added by looking at explicated design reasoning to get a more comprehensive and fine-grained understanding of the intuitive decision making process and design judgment. This study therefore set the stage for future studies on teachers' explicated design reasoning to incorporate literature on design conversations (see for instance Rapanta et al., 2013). Future research should endeavor to better understand how existing orientations are explicated. Methods of analyzing design talk were found useful. Yet as also insights into how conversations of groups reflect learning and situated cognition, more studies are needed to get a better understanding of the role of existing orientations, especially how they are used in the context of technology design.

Practical implications suggest how teachers should be supported in contexts in which they attempt to solve design problems. Because it is important but not their natural inclination, support to regular teachers should bring in subject-matter considerations. Additionally, the findings from this study suggest that most teachers would likely benefit from expertise on how technology could be used specifically for disciplinary learning. Such expertise should be provided in a way that coincides with their natural tendency to focus mostly on pedagogy related practical concerns. One approach would be to first use clear exemplary curriculum material or provide input before and during the design conversations on topics related to subject matter, technology or a combination of both. In such a case, before designing, teachers could gain a general understanding of what should be designed which is considered an effective support strategy in collaborative curriculum design (Handelzalts, 2009). With the ultimate goal of being able to provide adequate support, this study's empirical observation and analysis of teacher design activity constitute limited, yet helpful additions to understanding teacher decision making during curriculum development. 


\section{References}

Ben-Peretz, M. (1990). The teacher-curriculum encounter: freeing teachers from the tyranny of texts: State University of New York Press.

Borko, H. (2004). Professional Development and Teacher Learning: Mapping the Terrain. Educational researcher, 33(8), 3-15. doi: 10.3102/0013189x033008003

Borko, H., \& Putnam, R. T. (1996). Learning to teach. In D. C. B. R. C. Calfee (Ed.), Handbook of educational psychology (pp. 673-708). London, England: Prentice Hall International.

Buchanan, T. K., Burts, D. C., Bidner, J., White, V. F., \& Charlesworth, R. (1998). Predictors of the developmental appropriateness of the beliefs and practices of first, second, and third grade teachers. Early Childhood Research Quarterly, 13(3), 459-483. doi: http://dx.doi.org/10.1016/S0885-2006(99)80052-0

Clandinin, D. J., Connelly, F.M.,. (1992). Teacher as curriculum maker. In P. Jackson (Ed.), Handbook of research on curriculum (pp. 363-395). New-York, NY: Macmillan.

Cross, N. (1982). Designerly ways of knowing. Design Studies, 3(4), 221-227. doi: http://dx.doi.org/10.1016/0142-694X(82)90040-0

Cross, N. (2004). Expertise in design: an overview. Design Studies, 25(5), 427-441. doi: http://dx.doi.org/10.1016/j.destud.2004.06.002

Cviko, A., McKenney, S., \& Voogt, J. (2011). Teachers enacting a technology-rich curriculum for emergent literacy. Educational Technology Research and Development, 1-24.

Davis, E. A., Beyer, C., Forbes, C. T., \& Stevens, S. (2011). Understanding pedagogical design capacity through teachers' narratives. Teaching and Teacher Education, In Press, Corrected Proof. doi: DOI: 10.1016/j.tate.2011.01.005

de Kock, A., Sleegers, P., \& Voeten, M. J. M. (2005). New learning and choices of secondary school teachers when arranging learning environments. Teaching and Teacher Education, 21(7), 799-816. doi: 10.1016/j.tate.2005.05.012

Deketelaere, A., Kelchtermans, G.,. (1996). Collaborative curriculum development: an encounter of different professional knowledge systems. teachers and Teaching: theory and practice, 2(1), 16.

Dorst, K., \& Cross, N. (2001). Creativity in the design process: co-evolution of problemsolution. Design Studies, 22(5), 425-437. doi: http://dx.doi.org/10.1016/S0142694X(01)00009-6

Doyle, W., \& Ponder, G. A. (1977). The practicality ethic in teacher decision-making. Interchange, 8(3), 1-12. doi: 10.1007/bf01189290

George, J. M., \& Lubben, F. (2002). Facilitating teachers' professional growth through their involvement in creating context-based materials in science. International Journal of Educational Development, 22(6), 659-672.

Grossman, P. L. (1990). The Making of a Teacher: Teacher Knowledge and Teacher Education: Teachers College Press, Teachers College, Columbia University.

Handelzalts, A. (2009). Collaborative curriculum development in teacher design teams. (PhD Doctoral), Universiteit Twente, Enschede.

Hong, Y.-C., \& Choi, I. (2011). Three dimensions of reflective thinking in solving design problems: a conceptual model. Educational Technology Research and Development, 59(5), 687-710. doi: 10.1007/s11423-011-9202-9 
Hoogveld, A. W. M., Paas, F., \& Jochems, W. M. G. (2003). Application of an instructional systems design approach by teachers in higher education: individual versus team design. Teaching and Teacher Education, 19(6), 581-590.

Hoogveld, A. W. M., Paas, F., Jochems, W. M. G., \& van Merriënboer, J. J. G. (2001). The effects of a Web-based training in an instructional systems design approach on teachers' instructional design behavior. Computers in Human Behavior, 17(4), 363371.

Horn, I. S. (2010). Teaching Replays, Teaching Rehearsals, and Re-Visions of Practice: Learning From Colleagues in a Mathematics Teacher Community. Teacher College Records, 112(1), 34.

Jonassen, D. (2000). Toward a design theory of problem solving. Educational Technology Research and Development, 48(4), 63-85. doi: 10.1007/bf02300500

Jonassen, D. (2012). Designing for decision making. Educational Technology Research \& Development, 60(2), 341-359. doi: 10.1007/s11423-011-9230-5

Kerr, S. T. (1981). How teachers design their materials: Implications for instructional design. Instructional Science, 10(4), 363-378.

Koehler, M. J., \& Mishra, P. (2005). What happens when teachers design educational technology? The development of technological pedagogical content knowledge. Journal of Educational Computing Research, 32(2), 131-152.

Koehler, M. J., Mishra, P., \& Yahya, K. (2007). Tracing the development of teacher knowledge in a design seminar: Integrating content, pedagogy and technology. Computers \& Education, 49(3), 740-762.

Lawson, B. (2004). Schemata, gambits and precedent: some factors in design expertise. Design Studies, 25(5), 443-457. doi: http://dx.doi.org/10.1016/j.destud.2004.05.001

Lera, S. G. (1981). Empirical and theoretical studies of design judgement: a review. Design Studies, 2(1), 19-26. doi: http://dx.doi.org/10.1016/0142-694X(81)90025-9

Little, J. W. (2002). Locating learning in teachers' communities of practice: opening up problems of analysis in records of everyday work. Teaching and Teacher Education, 18(8), 917-946. doi: Doi: 10.1016/s0742-051x(02)00052-5

McKenney, S., \& Voogt, J. (2009). Designing technology for emergent literacy: The PictoPal initiative. Computers \& Education, 52, 719-729.

Nelson, H. G., \& Stolterman, E. (2012). The Design Way: Intentional Change in an Unpredictable World: University Press Group Limited.

Parke, H. M., \& Coble, C. R. (1997). Teachers designing curriculum as professional development: A model for transformational science teaching. Journal of Research in Science Teaching, 34(8), 773-789.

Rapanta, C., Maina, M., Lotz, N., \& Bacchelli, A. (2013). Team design communication patterns in e-learning design and development. Educational Technology Research and Development, 61(4), 581-605. doi: http://dx.doi.org/10.1080/0158791960170103;

Remillard, J. T. (2005). Examining Key Concepts in Research on Teachers' Use of Mathematics Curricula. Review of Educational Research, 75(2), 211-246.

Rittel, H. J., \& Webber, M. (1973). Dilemmas in a general theory of planning. Policy Sciences, 4(2), 155-169. doi: 10.1007/BF01405730

Stempfle, J., \& Badke-Schaub, P. (2002). Thinking in design teams - an analysis of team communication. Design Studies, 23(5), 473-496. doi: http://dx.doi.org/10.1016/S0142-694X(02)00004-2

Stenhouse, L. (1975). An introduction to curriculum research and development: Heinemann.

Stipek, D. J., \& Byler, P. (1997). Early childhood education teachers: Do they practice what they preach? Early Childhood Research Quarterly, 12(3), 305-325. 
Strauss, A., \& Corbin, J. M. (1998). Basics of Qualitative Research: Techniques and Procedures for Developing Grounded Theory: SAGE Publications.

Turbill, J. (2001). A Researcher Goes to School: Using Technology in the Kindergarten Literacy Curriculum. Journal of Early Childhood Literacy, 1(3), 255-279. doi: $10.1177 / 14687984010013002$

Walker, D. F. (1971). A Study of Deliberation in Three Curriculum Projects. Curriculum Theory Network(7), 118-134. 